
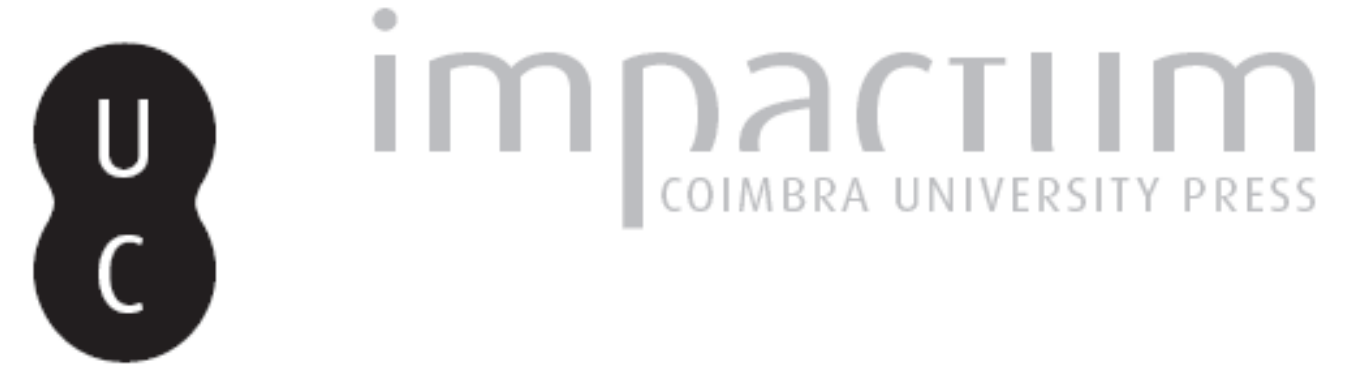

\title{
Não há utopias portuguesas
}

\author{
Autor(es): Medina, João
}

Publicado por: Imprensa da Universidade de Coimbra

URL persistente:

URI:http://hdl.handle.net/10316.2/43957

DOI:

DOI:https://doi.org/10.14195/2183-8925_2_4

Accessed : $\quad$ 26-Apr-2023 10:16:19

A navegação consulta e descarregamento dos títulos inseridos nas Bibliotecas Digitais UC Digitalis, UC Pombalina e UC Impactum, pressupõem a aceitação plena e sem reservas dos Termos e Condições de Uso destas Bibliotecas Digitais, disponíveis em https://digitalis.uc.pt/pt-pt/termos.

Conforme exposto nos referidos Termos e Condições de Uso, o descarregamento de títulos de acesso restrito requer uma licença válida de autorização devendo o utilizador aceder ao(s) documento(s) a partir de um endereço de IP da instituição detentora da supramencionada licença.

Ao utilizador é apenas permitido o descarregamento para uso pessoal, pelo que o emprego do(s) título(s) descarregado(s) para outro fim, designadamente comercial, carece de autorização do respetivo autor ou editor da obra.

Na medida em que todas as obras da UC Digitalis se encontram protegidas pelo Código do Direito de Autor e Direitos Conexos e demais legislação aplicável, toda a cópia, parcial ou total, deste documento, nos casos em que é legalmente admitida, deverá conter ou fazer-se acompanhar por este aviso.

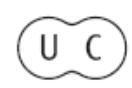


INSTITUTO DE HISTÓRIA E TEORIA DAS IDEIAS

\title{
REVISTA DE HISTÓRIA $D A S$ IDEIAS
}

\author{
VOL. II
}

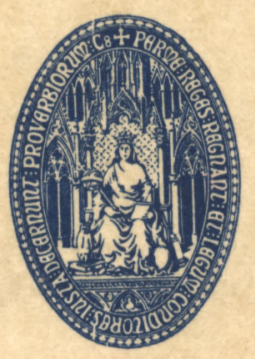

UNIVERSIDADE DE COIMBRA

$1978-1979$ 


\title{
NÃO HÁ UTOPIAS PORTUGUESAS
}

\author{
"Nada the perguntámos acerca daqueles \\ monstros tão famosos outrora que já \\ não têm interesse algum: Scilas, Celenos, \\ Lestrigões, antropófagos e outras harpias \\ do mesmo género que existiam quase por \\ toda a parte. O que é mais raro e digno \\ de interesse é uma sociedade sã e sabia- \\ mente organizada.»
}

TOMÁs MORUS, «Utopia» (1516).

Apesar de o livro de Morus que criou o neologismo e o conceito de Utopia (à letra: um «não-lugar», u-topos) estar ligado aos descobrimentos portugueses pela dupla razão de o seu narrador ser o navegante luso Rafael Hitlodeu e pelo facto de no dealbar do quinhentismo o pequeno Portugal ter já no seu activo diversos feitos marítimos notáveis como a descoberta do caminho marítimo para a Índia e o achamento brasílico, a verdade é que essa grande aventura da expansão e o verdadeiro deslumbramento existencial que ele suscitou desde que os europeus se meteram a dilatar por via aquática os seus limites geográficos até ali confinados afinal à bacia mediterrânica não suscitaram entre nós o florescer duma literatura comparável àquela que na Inglaterra, na França ou na Itália produziram os Morus, os Rabelais (a abadia gargantuesca de Thélème é uma utopia sibarita e libertária, talvez a primeira "Comuna» anarca da História...), os Campanella e tantos outros arquitectos mentais de cidades imaginárias (1).

(1) Damos a utopia o sentido corrente do termo, mas lendo-o com uma conotação sociológica, tal como o concebeu Karl Mannheim (Ideologia e Utopia, 1929): a ideologia está ligada a interesses dos grupos dominantes e tem uma função conservadora ou legitimista, enquanto que as utopias se prendem com os estratos políticos e sociais geralmente oprimidos e desempenham uma função dinamizadora e contes- 


\section{1 - Ausência de utopias ibéricas}

A Utopia de Morus é dada à estampa em Lovaina em 1515-1516, estando a sua origem enraizada nessa Flandres mercantil tão intimamente associada aos negócios e às aventuras lusitânicas. É à sombra da Notre-Dame de Antuérpia que o conselheiro britânico bate o papo com o seu amigo Pierre Gilles e que este lhe apresenta um marinheiro de tez escura e pele curtida por viagens ao lado de Vespúcio e outros argonautas do épico final do séc. XV. Chama-se Rafael Hitlodeu (1) o estrangeiro, andou pelos oceanos fora e, como o seu nome o indica, gosta de longas conversas: «hythlos», a palavra grega na raíz do nome do nosso patrício, significa «tagarelice» (2), expressão cara a Platão, um dos autores preferidos do futuro decapitado inglês. Ora o nosso Rafael é de facto um tagarela e não pára de contar aos

tatária das instituições e ordens sociais vigentes, situando os seus objectivos numa perspectiva virada para o futuro. As ideias que, «a posteriori», se revelaram como representações deformadas da ordem social são, assim, ideológicas, enquanto que aquelas que se realizaram adequadamente na ordem social ulterior eram «utopias relativas", segundo o critério sociológico de Mannheim; veja-se a trad. brasileira de Ideologia e Utopia, trad. de Sérgio Magalhães Santeiro, Rio de Janeiro, Zahar Editores, 1968; existe uma trad. francesa incompleta: Ideologie et Utopie, Paris, M. Rivière, 1956; ed. alemã recente: Ideologic und Utopie, Francoforte, G. Schulte-Bulmke, 1965.

(1) Veja-se Luís DE MATos, "A Utopia de Tomás More e a Expansão portuguesa", separata de Estudos Politicos e Sociais, vol. IV, n. ${ }^{\circ}$ 3, 1966, pp. 809-820, Lisboa, Instituto Superior de Ciências Sociais e Política Ultramarina, 14 p. Quanto a saber se Hitlodeu é um personagem real ou imaginário, Luís de Matos afirma que "há indícios muito fortes para acreditar que o marinheiro português não é uma pura e simples invenção do autor da Utopia) (op. cit., p. 5), sendo verosímil o périplo descrito e plausíveis as descrições geográficas sugeridas («a geografia do texto de More não é fantasista mas, pelo contrário, de grande precisão», p. 8). A própria ilha utópica teria um fundamento, correspondendo às regiões orientais conhecidas pelos portugueses desde os começos do séc. XVI, coincidindo o texto do inglês com o relato dum Duarte Barbosa sobre Ceilão, a Índia e outras paragens do longínquo Oriente. Em suma, conclui Luís de Matos, «Hitlodeu não é uma criação imaginária de More.» (pp. 13-14).

(2) «Hythlos» significa não só «tagarelice» mas também "conversação inútil» ou «sandice»; o verbo «hythleo» significa «dizer ninharias» e "chancear». Toda a Utopia fervilha destes trocadilhos. Assim, por exemplo, a capital, que se chama Amaurota (cidade fantasma) fica sobre o rio Anidro (sem água), é governada por Ademos (príncipe sem povo) e habitada por Alxopolitas (cidadãos sem cidade). 
outros dois as suas peregrinações pelo novo mundo achado e descrito por toda uma legião de andarilhos ou simples embarcadiços e repórteres, da altura ou posteriores, homens como Pero Vaz de Caminha (o tabelião do acto de surgimento das terras de Vera Cruz), Álvaro Velho, o Pigafetta de Vasco da Gama, António Tenreiro, "globe-trotter» porfiado que da Índia veio a pé até à praia lusitana, atravessando terras do Grão-Turco, Frei Gaspar da Cruz, P.e Francisco Álvares, Manuel Pinheiro, Gabriel Soares de Sousa, Frei Pantaleão de Aveiro, Frei António dos Santos, Fernão Mendes Pinto, P.e António de Andrade, P.e Manuel de Almeida, Duarte Barbosa, Gaspar Correia, João de Barros, o próprio Camões épico, P.e Manuel Godinho e tantos outros viajantes que, do Paço das Naus a Taprobana, de Cabeceiras de Basto a Calecute ou à foz do Amazonas, de Alcântara ao Grão Cataio, à China ou mesmo ao Tibete, passando por Arábias e Etiópias, dobrando cabos tormentosos ou assistindo ao surgir das costas índicas a bordo de naus pioneiras como as imortais $S$. Gabriel ou Bérrio, testemunharam ou relataram o achamento de velhos mundos novos que portugueses e espanhóis, à compita, iam escavando dos negrumes dos antigos portulanos. O estranho porém é que, estando nós na origem como que factual da Utopia, não se acha em toda a literatura de viagens acima referida nada de comparável ao livro de Morus.

Porquê? Antes de mais, diga-se desde já que tal fenómeno ocorre também com os nossos émulos ibéricos dos séculos XV e XVI: como o sublinhava recentemente Luís Núñez (1), não há na literatura castelhana nada que se equipare às obras utópicas de Morus, Bacon ou Campanella, a menos que se queira incluir no género a obra-prima de Cervantes, como aliás acaba de o intentar José António Maravall com o seu estudo Utopia y Contrautopia en el Quijote (2), partindo do pressuposto de que há no humanismo quixotesco das armas um conteúdo utópico. Mas o mesmo Ladevese lembra que a ausência do género propriamente utopista em Espanha é compensado, por um lado, por um surto muito especial de utopia individual, que é a mística, e por aquilo a que ele mesmo chama «utopias da praxis», ou seja, pela substituição do conceito pela acção, como sucede com a experiência

(1) Veja-se Luís NúÑEZ LAdeVESE, «Sinapia», in Historia 16, n. ${ }^{\circ}$, Janeiro de 1977, pp. 126-129.

(2) José António Maravall, Utopia y Contrautopia en el "Quijote», Santiago de Compostela, Editorial Pico Sacro, 1976. 
comunista dos jesuítas no Paraguai. Fosse como fosse, faltou aos primeiros povos navegantes modernos o sentido utopizante e o género mesmo inaugurado pelo inglês Morus, não propriamente por falta de lirismo ou de fantasia - não viu Georges Duveau no «De optimo reipublicae regnum statu deque nova insula Utopiae» (assim se chamava no original latino o livro de São Tomás Morus) um «tom de positivismo gelado» (Sociologie de l'Utopie) (1)? - , mas por carência que há que situar noutras regiões da cultura ou da sensibilidade. Mas onde? Quais as razões da ausência de utopismo autêntico na nossa aliás tão abundante literatura de viagens? Não pretendemos responder a semelhante pergunta. Fazê-lo antemostra-se mais do que árduo, pelo que nos contentamos em sublinhar o facto, o que desde já parece, ao que sabemos, novo.

\section{2 - Monstros ou cidades felizes?}

Se percorrermos a nossa literatura quinhentista de viagens não deparamos, é verdade, com algo de equivalente ao famoso livro de Morus: os nossos viajantes prendem-se mais com o exotismo ou o deslumbramento próprio de quem julga ter encontrado o paraíso perdido (2) do que com o raciocínio político que, ao fim e ao cabo, está na base mesma da obra de Morus, escrita 16 anos depois da descoberta do Brasil, quase vinte anos depois da chegada de Gama à Índia e menos de um quarto de século após o fecundo erro de cartografia quimérica de Colombo, e três anos antes de Magalhães iniciar a primeira circum-navegação planetária: o próprio conselheiro recalcitrante de Henrique VIII nos adverte de que, afinal, o lado exterior, exótico e pitoresco das viagens dos descobrimentos pouco ou nada interessa, já que os dois interlocutores do português Hitlodeu acham menos interessantes

(1) Georges Duveau, Sociologie de l'Utopie et autres "Essais» (obra póst., introd. de A. Canivez), Paris, P.U.F., 1961; p. 79.

(2) Veja-se Sérgio Buarque de Holanda, Visão do Paraíso. Os motivos edênicos no descobrimento e colonização do Brasil (2.a ed.), São Paulo, Companhia Editora Nacional, 1969. Segundo Buarque de Holanda, o deslumbramento das descobertas suscitou uma floração de literatura impregnada de «multiforme romantismo insular» cuja marca é visível em autores tão diversos como Morus, Camões e Defoe (p. 267). 
os relatos acerca de «monstros» como os lestrigóes e os antropófagos do que a eventual descoberta dum recanto do globo governado por gente justa e sensata: «O que é mais raro e digno de interesse é uma sociedade sã e sabiamente organizada.» (Utopia) (1). Ora as histórias do nosso patrício só teriam interesse na medida em que, passando por cima do exotismo fácil dos exploradores quatrocentistas e quinhentistas, oferecessem aos ouvintes o relato mais proveitoso e metafísico duma sociedade bem organizada, a tal península que Utopus decidiu seccionar do continente para nela tentar uma nova república (Politeia) de cariz platónico, isto é, dirigista, planificadora e comunitária. Os monstros nada interessam, são ninharias ou tagarelices para o grande público que lê coisas mirabolantes e gosta de ouvir falar de sereias onde, na verdade, há apenas lemantinos de peitos fartos onde os pobres marujos de Colombo ou Vespúcio julgam ver seios de alabastro, ou de horríveis monstros aquáticos onde afinal se escondem honestíssimos cetáceos. O que é, afinal, novo e interessante na obra de Morus é aquele seu interesse em aproveitar as grandes esperanças e os fantásticos deslumbramentos das descobertas para neles visionar, arquitecto social, o modo de, como ele mesmo diz, «regenerar cidades, povos e reinos da velha Europa» (2). Não lhe interessam lendas ou maravilhas, mas a regeneração política e social do velho mundo quando este encontra um Novo Mundo. Assim haviam também de discorrer, cada qual a seu especial modo, Shakespeare, Bacon, Montaigne e, muito mais tarde, Rousseau, Swift, Butler, etc..

\section{3 - A ilha undivaga de Camões}

Voltando ao princípio: suscitámos a utopia mas, tal como os nossos vizinhos ibéricos, não engendrámos utopismos, não obstante a vasta movimentação que operámos com as nossas viagens marítimas ou terrestres. Nem mesmo o poema que na nossa língua ergueu às proporções de epopeia incorruptível os feitos marítimos que se resumem na odisseia de Vasco da Gama nos apresenta afinal a utopia que seria de esperar de um tão atento leitor dos antigos, e em especial de Platão,

(1) Citamos a tradução portuguesa d'A Utopia de Morus, da autoria de José Marinho, publicada em Lisboa por Guimarães Editores, em 1972, p. 16.

(2) Morus, op. cit., loc. cit. 
como o foi Camões. Embora tendo publicado o seu grandioso poema de 1572, quase 40 anos depois de Morus ter terminado a sua carreira terrestre, decapitado por desagradar ao seu soberano, o platonizante poeta d'Os Lusíadas não se aproxima do utopismo do ateniense que tentou reformar Siracusa como conselheiro do tirano Dionísio ou do seu distante émulo britânico que se opôs com subtilezas teológicas a um monarca garanhão que queria à viva força desposar mais uma concubina, essa Ana Bolena que, entre outras coisas más, havia de ser responsável pelo fim do pobre humanista no cadafalso, em 1535.

Camões não utopiza. O seu célebre episódio da Ilha dos Amores, no canto IX, não transcende afinal a simples perífrase do paraíso (assim o viu, por exemplo, em 1849, José Gomes Monteiro no seu opúsculo sobre o caso) (1). Aquela flutuante «ilha angélica» (canto IX, est. 89) que Vénus manda de recompensa aos companheiros de Gama como prémio de tanta tormenta passada na viagem do Restelo a Calecute, para que ali repousem das «Lusitânicas fadigas» e possam enfim, já de regresso à praia lusa, "Refocilar a lassa humanidade» (canto IX, estrofes 38 e 30, respectivamente), não passa afinal da adaptação oportuna e maravilhosamente recriada dum episódio da Odisseia, a da recepção do prófugo Ulisses no palácio dos Feácios ${ }^{(2)}$, allegro tradicional no género epopeico, com o seu equivalente no palácio de Alcina de Ariosto ou os jardins de Armida de Torquato Tasso. À Chipre deleitosa de Homero sucede aqui, na epopeia da viagem de Gama, aquela «ínsula divina, / Ornada de esmaltado e verde arreio» onde

(1) Na sua Carta ao Ilmo. Sr. Tomás Norton sobre a situação da Ilha de Vénus (Porto, Tipografia de S. J. Pereira, 1849), José Gomes Monteiro procura mostrar que a ilha undívaga do canto IX d'Os Lusiadas tinha um certo fundamento geográfico e histórico, sendo possível conotá-la com qualquer ilha para as bandas de Zanzibar: aquela «risonha e inimitável ficção» (p. 20) erótica da epopeia de Camões teria assim o seu protótipo no mundo real. O próprio roteiro de Vasco da Gama autorizaria. parece, tal conclusão. Observe-se que Gomes Monteiro escreveu o seu opúsculo em réplica às observações de Alexandre de Humboldt no seu Cosmos acerca da ilha camoneana (cf.op. cit., pp. 45 ss); o subtítulo do opúsculo de Gomes Monteiro é como se segue: «E em defesa de Camões contra uma arguição, que na sua obra intitulada Cosmos, lhe faz o Sr. Alexandre de Humboldt».

(2) Veja-se a descrição do palácio dos Feácios e do seu grande horto sempre maduro na tradução portuguesa da Odisseia de Homero, pelos Padres E. Dias Palmeira e M. Alves Correia, Lisboa, Livraria Sá da Costa, 4. ${ }^{a}$ ed., 1972, pp. 92 ss. 
«as aquáticas donzelas» esperam os «fortíssimos barões» para lhes darem o merecido prémio de tão dilatada epopeia gloriosa (estrofes 21 e 22), ilha de Amores que a amorosa Vénus, intercedendo na celestial corte pelos seus protegidos, os filhos de Luso, diz querer mandar, espécie de deliciosa Ogígia undívaga, ao encontro dos nautas de regresso a casa, vergel onde as filhas de Nereu, de «amor dos Lusitanos incendidas / Que vem de descobrir o novo mundo» (est. 40), prodigalizem a marujos tão longamente privados dos prazeres da carne, «mil refrescos e manjares, / Com vinhos odoríferos e rosas» e, sobretudo, «formosos leitos e elas mais formosas», em suma «mil deleites não vulgares» (est. 41). Naturalíssima e, bem vistas as coisas, demasiado humana recompensa para os lusos Jasões após tão longa quanto casta epopeia. Não há porém nesta perfumada Citera para marujos famintos onde os esperam «ninfas amorosas / De amor feridas, para lhes entregarem / Quanto delas os olhos cobiçarem» (est. 41), simples alegoria da glória que recompensa os grandes feitos e os homens que realizam «obras valerosas» (est. 89) (1), não há pois nesta reparadora e lasciva ínsula angélica aquela metafísica inquietação que faz da Utopia político-social de Morus um dos primeiros grandes ensaios da arquitectura conceptual política moderna, ao lado de outros imaginativos inventores da Liberdade como Morelly, Rousseau, Babeuf, Fourier, William Morris, Campanella, etc..

Tendo passado cinco anos na curiosa ilha sabiamente governada, Rafael Hitlodeu é afinal o único viajante português de quinhentos que se desprende do exotismo da literatura de descobertas e dos guias dos novos mundos achados para se erguer, graças à mente cogitativa de Morus, à estatura dum novo Platão, a recomeçar a sua utópica República que em vão quisera ver imitada em Siracusa. Mas Hitlodeu, apesar da tez muito morena, da barba comprida e de ter capitaneado navios na companhia de Vespúcio e outros, não passa talvez dum ser imaginário criado

(1) Os «deleites desta Ilha» (est. 89) - adverte-nos Camões - não passam dos "prémios que reparte / Por feitos imortais e soberanos / O mundo cos barões que esforço e arte / Divinos os fizeram, sendo humanos» (est. 91) (à qual Camões, pela boca de Vénus acrescenta algumas exortações moralizantes: «ponde na cobiça um freio duro / E na ambição também, que indignamente / Tomais mil vezes, e no torpe e escuro / Vício da tirania infame e urgente...» (est. 93), «dai na paz as leis iguais...» (est. 94) e «sereis entre os Heróis esclarecidos / E nesta Ilha de Vénus recebidos» (est. 95). 
por um malogrado político inglês, canonizado pela Santa Madre Igreja quatro séculos depois da sua execução. E é isto tudo quanto há de português no mundo dos utopismos: um personagem português com um nome formado a partir do grego, uma espécie de Duarte Barbosa ( $\left.{ }^{1}\right)$ que, em vez de ter sucumbido na mesma viagem de Fernão de Magalhães, em 1521, teria contado a Gilles e a Morus o que vira pelo Oriente.

JoÃo Medina

(1) Duarte Barbosa (1480?-1521), navegador português, é autor dum livro, composto em 1516 mas só três séculos depois editado em português (1821), onde relata o que viu e ouviu no Oriente. Companheiro de Fernão de Magalhães, faleceu poucos dias depois deste. 